\title{
Evaluation of niobium as candidate electrode material for dc high voltage photoelectron guns
}

\author{
M. BastaniNejad, Md. Abdullah Mohamed, and A. A. Elmustafa \\ Old Dominion University, Norfolk, Virginia 23529, USA
}

\begin{abstract}
P. Adderley, J. Clark, S. Covert, J. Hansknecht, C. Hernandez-Garcia, M. Poelker, R. Mammei, and K. Surles-Law
Thomas Jefferson National Accelerator Facility, Newport News, Virginia 23606, USA
\end{abstract}

P. Williams

NASA Langley Research Center, Hampton, Virginia 23681, USA

(Received 2 May 2012; published 17 August 2012)

\begin{abstract}
The field emission characteristics of niobium electrodes were compared to those of stainless steel electrodes using a DC high voltage field emission test apparatus. A total of eight electrodes were evaluated: two 304 stainless steel electrodes polished to mirrorlike finish with diamond grit and six niobium electrodes (two single-crystal, two large-grain, and two fine-grain) that were chemically polished using a buffered-chemical acid solution. Upon the first application of high voltage, the best large-grain and single-crystal niobium electrodes performed better than the best stainless steel electrodes, exhibiting less field emission at comparable voltage and field strength. In all cases, field emission from electrodes (stainless steel and/or niobium) could be significantly reduced and sometimes completely eliminated, by introducing krypton gas into the vacuum chamber while the electrode was biased at high voltage. Of all the electrodes tested, a large-grain niobium electrode performed the best, exhibiting no measurable field emission $(<10 \mathrm{pA})$ at $225 \mathrm{kV}$ with $20 \mathrm{~mm}$ cathode/anode gap, corresponding to a field strength of $18.7 \mathrm{MV} / \mathrm{m}$.
\end{abstract}

DOI: 10.1103/PhysRevSTAB.15.083502

PACS numbers: 29.25.Bx, 79.70.+q, 29.25.Pj

\section{INTRODUCTION}

DC high voltage photoguns provide electron beams for accelerators [1]. Some applications require high bunch charge [2] or small beam emittance [3] and for these circumstances it is beneficial to operate the photogun at very high bias voltage $(\sim 500 \mathrm{kV})$ and high field strength $(>10 \mathrm{MV} / \mathrm{m})$ to produce a relativistic beam insensitive to space charge forces that degrade beam quality. The first DC high voltage photogun used at an accelerator operated at $100 \mathrm{kV} \mathrm{[4]} \mathrm{and} \mathrm{many} \mathrm{photoguns} \mathrm{operating} \mathrm{near} \mathrm{this} \mathrm{voltage}$ were constructed shortly afterwards [5-10]. The Jefferson Lab Free Electron Laser employed the first photogun to operate at significantly higher voltage, $\sim 320 \mathrm{kV}$ [11]. Today a number of photoguns operate at comparable values albeit still lower voltage than desired [12-15].

Operation at voltage $\gg 100 \mathrm{kV}$ is difficult due to field emission and breakdown from the cathode electrode and/or the electrode support structure. Low-level field emission can degrade the vacuum conditions and reduce photocathode lifetime, especially when delicate GaAs photocathodes are used. High levels of field emission can damage the ceramic insulator, historically a large hollow cylinder with electrode support structure passing through its bore.

Published by the American Physical Society under the terms of the Creative Commons Attribution 3.0 License. Further distribution of this work must maintain attribution to the author(s) and the published article's title, journal citation, and DOI.
Strategies to reduce field emission and protect the high voltage insulator are being actively pursued. Large dimensions help reduce the field strength at some locations within the photogun but can introduce considerable expense when insulator flanges exceed 13 inches in diameter. Large dimensions also make it more difficult to achieve ultrahigh vacuum. An inverted gun design [16] reduces the amount of metal biased at high voltage, and if field emission occurs, the electrons are less likely to strike the insulator due to the orientation of the electrostatic field lines. Segmented insulators [9] successfully shield the insulator from field emission and a recent demonstration indicates successful operation at $500 \mathrm{kV}$ [17]. Field emission coatings [18] once seemed promising but unfortunately, serve to trap gas which is liberated during high voltage processing. All of these approaches are reasonable to pursue, however, it is best to prevent field emission altogether.

Furuta et al. [19] demonstrated that a molybdenum cathode and titanium anode were superior to stainless steel electrodes, exhibiting less than $1 \mathrm{nA}$ field emission at field strength $>100 \mathrm{MV} / \mathrm{m}$; however, all of these measurements were performed at relatively low voltage and with small cathode/anode gaps. Similar reports can be found in literature of electrodes exhibiting small amounts of field emission at very high field strength [20], however photogun groups encounter problematic field emission at $\sim 10 \mathrm{MV} / \mathrm{m}$ or lower. The disparity between the encouraging results with small gaps and disappointing results obtained with actual photoguns indicates that field emission 
studies must be carried out using a test apparatus that closely resembles the actual photogun.

Superconducting radio frequency (SRF) accelerating cavities are made of niobium because of its electrical characteristics at liquid helium temperature. Niobium can provide very high $\mathrm{rf}$ accelerating gradient, $>40 \mathrm{MV} / \mathrm{m}$, with surface fields in excess of $100 \mathrm{MV} / \mathrm{m}$ [21]. Niobium has a work function comparable to stainless steel and with similar hardness. One of the most appealing features is that the material can be chemically polished, rather than mechanically polished with diamond paste, which is very labor intensive. Easy access to niobium and readily available infrastructure and expertise at Jefferson Lab provided the motivation to evaluate niobium as candidate electrode material for DC high voltage photoguns, even though it would not be cooled to utilize its superconducting nature.

The objective of these tests was to determine if niobium electrodes can operate at $500 \mathrm{kV}$ bias voltage inside DC high voltage photoguns, without field emission at field strength between 12 to $15 \mathrm{MV} / \mathrm{m}$. The test apparatus used for these measurements provided voltage up to $225 \mathrm{kV}$ but hopefully these results provide a more useful extrapolation to performance at $500 \mathrm{kV}$ than previously reported work at $\sim 100 \mathrm{kV}[19,20]$.

\section{THE ORIGINS OF FIELD EMISSION}

The Fowler-Nordheim theory of field emission is based on a quantum mechanical solution to the Schroedinger equation [22] whereby electrons tunnel through a potential barrier in the presence of a high electric field. The expression below successfully describes the observed "prebreakdown" functional form of field emission from a single emitter [23]:

$$
I=J \cdot A_{e}=C_{1} A_{e} \beta^{2} E^{2} e^{-C_{2} / \beta E},
$$

where $I$ is the field emission current in amps, $J$ is the field emission current density, $A_{e}$ is the area of the field emitter in units of $m^{2}, E$ is the average surface field strength, $\beta$ is the field enhancement factor defined as the ratio of the emitter electric field to the average surface field, and factors $C_{1}$ and $C_{2}$ are fundamental constants given by

$$
\begin{gathered}
C_{1}=\frac{1.54 \times 10^{-6} \times 10^{4.52 \phi^{-0.5}}}{\phi} \\
C_{2}=6.53 \times 10^{9} \phi^{1.5},
\end{gathered}
$$

where $\varphi$ is the work function of the material, typically $\sim 4.5 \mathrm{eV}$ for most electrode materials.

Although Eq. (1) is very well known, it is generally not used to predict specific electrode performance. This is because the parameters $A_{e}$ and $\beta$ are difficult to constrain. Mostly, Eq. (1) is used to verify that the observed current follows the expected field emission functional form, and not, for example, electrical breakdown.

Frequently, the field strength is considered the most important factor in determining field emission performance, and often the significance of cathode bias voltage is overlooked. But the cathode bias voltage sets the energy of the field emitted electrons which in turn influences the energy spectrum of the ions that back-bombard the cathode electrode and the amount of gas liberated from the anode due to electron stimulated desorption. According to Ref. [23], field strength is the most important consideration for small gaps $(<2 \mathrm{~mm})$ whereas voltage becomes the important parameter for gaps $>5 \mathrm{~mm}$.

Minimizing the field enhancement factor is very important and to this end, experimenters strive to eliminate sharp tips, typically via a combination of mechanical and chemical polishing. Lately, there is much discussion related to microparticulate contamination on the cathode surface which serves to enhance the field strength. Everyone agrees contamination is something to avoid, and some obvious steps are taken to minimize it: clean electrode preparation and the construction of the apparatus in a dust-free environment, for example.

The field enhancement factor $\beta$ is difficult to quantify beforehand but can be determined empirically by generating Fowler-Nordheim logarithmic line plots (see Fig. 5 as an example). The expression below is derived from Eq. (1) and the slope of the line provides a determination of $\beta$ :

$$
\text { slope }=\frac{d\left(\log _{10} I / E^{2}\right)}{d(1 / E)}=-\frac{2.85 \times 10^{9} \varphi^{1.5}}{\beta} .
$$

The intercept of the Fowler-Nordheim line plot with the $y$ axis provides a means to determine the emission area as illustrated by Eq. (5) below:

$$
\begin{aligned}
\text { intercept } & =\log _{10}\left(I_{F} / E^{2}\right)_{E \rightarrow \infty} \\
& =\log _{10}\left[\frac{1.54 \times 10^{-6} A_{e} \beta^{2} \times 10^{4.52 \varphi^{-0.5}}}{\varphi}\right] .
\end{aligned}
$$

The expressions above assume a single field emitter tip, which might not be a valid assumption for photogun electrodes that are very large. The merit of Eq. (5) in terms of evaluating real photogun electrodes will be discussed below.

Each electrode was characterized by measuring field emission current as a function of voltage and average field strength, as well as using a Fowler-Nordheim line-plot analysis to estimate the field enhancement factor and emitter area.

\section{EXPERIMENT DESCRIPTION}

Pierce-type cathode electrodes with $25^{\circ}$ focusing angle (6.35 $\mathrm{cm}$ diameter, $2.85 \mathrm{~cm}$ thick) were attached to an inverted insulator that extends into the ultrahigh vacuum test chamber (Fig. 1). Each electrode had a shape identical to electrodes used at the Continuous Electron Beam Accelerator Facility (CEBAF) for many years [24] with a hole in the middle $(1.28 \mathrm{~cm}$ diameter) to accommodate a GaAs photocathode if it were used in an actual polarized 

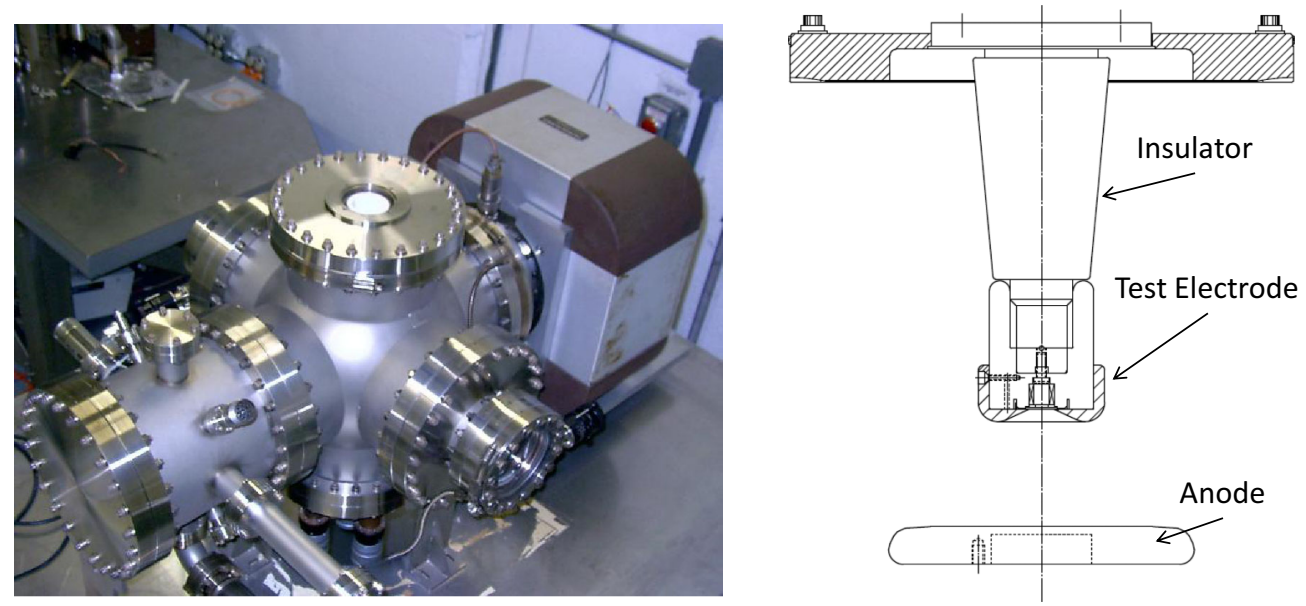

FIG. 1. (left) Photograph of the dc high voltage field emission test stand used to evaluate each cathode electrode, (right) a schematic view of the insulator, test electrode, and anode used to collect the field emission.

photogun. However for these tests, a piece of polished stainless steel was used in place of the GaAs photocathode.

The anode was a flat plate with a Rogowski edge profile, electrically isolated from ground and attached to a sensitive current meter (Keithley electrometer model 617). The anode could be moved up or down to vary the cathode/ anode gap and therefore the field strength. Two different anodes were used for these tests: a 304 stainless steel anode for evaluation of the diamond-paste-polished (DPP) 304 stainless steel cathode electrodes and a fine-grain niobium anode for evaluation of all the niobium cathode electrodes. The stainless steel anode was polished with 600 grit silicon carbide paper and $6 \mu \mathrm{m}$ diamond paste. The fine-grain niobium anode was chemically polished.

A $-225 \mathrm{kV}$ commercial high voltage power supply was used for the experiment. The high voltage power supply and the ceramic insulator accommodate "industry standard" high voltage cables with R-28 connectors. A $100 \mathrm{M} \Omega$ conditioning resistor was placed in series with the cathode electrode via an oil tank and served to protect the apparatus in case of sudden discharge of stored energy. The resistor also serves to protect the electrode via a negative feedback mechanism-as current increases, a larger voltage drop occurs across the resistor, reducing voltage at the electrode.

Each test electrode underwent similar preparation steps before installation as described below. Prior to the application of high voltage, the entire vacuum apparatus was baked at $200^{\circ} \mathrm{C}$ for 30 hours to achieve vacuum level in the -11 Torr range. Vacuum pumping was provided by a 220 L/s ion pump and a SAES Getters GP-500 nonevaporable getter pump which was partially activated during the bakeout. Every effort was made to keep the vacuum conditions constant from sample to sample, but depending on the amount of water vapor that was introduced into the apparatus upon venting and replacing the electrode, the vacuum could vary by factors of two or three between tests.
An assessment of the field emission properties of each test electrode involved monitoring vacuum level inside the apparatus, x-ray radiation near the apparatus, and anode current while increasing the voltage applied to the cathode electrode. High voltage was first applied to the electrode using the largest cathode/anode gap of $50 \mathrm{~mm}$. Upon successful high voltage processing (defined below), the gap could be decreased to achieve higher field strength. The smallest gap was $20 \mathrm{~mm}$ and provided maximum field strength of $\sim 20 \mathrm{MV} / \mathrm{m}$ when the cathode was biased at $-225 \mathrm{kV}$. Gap spacing less than $20 \mathrm{~mm}$ was avoided, as small gaps sometimes produced catastrophic breakdown and electrode damage.

Voltage was applied to each electrode and increased gradually while maintaining anode current less than a few nanoamperes. During processing, field emission sites would "burn off" and field emission current would become more stable. An electrode was considered fully processed when field emission current was stable to within a few percent of the average value. It was not uncommon for this to take many hours.

High voltage processing was not always successful: sometimes a field emission site (or sites) would be produced that would not burn off. This typically happened at the smallest gaps and highest field strengths. Elimination of stubborn field emitters often required krypton processing (described below), or worst case, the electrode was removed and repolished.

\section{A. Diamond-paste polishing of stainless steel}

The field emission characteristics of niobium electrodes were benchmarked against those of conventional DPP stainless steel electrodes that had been used successfully for many years inside one of the CEBAF $100 \mathrm{kV}$ spin polarized photoelectron guns. The DPP stainless steel electrodes were manufactured from vacuum arc-remelt 304 stainless steel. After being cut to shape with 
hydrocarbon-free lubricants, each electrode was polished on a potter's wheel with silicon carbide paper of increasingly finer grit (300 and then 600 particles/in ${ }^{2}$ ) followed by polishing with diamond grit $(6 \mu \mathrm{m}, 3 \mu \mathrm{m})$. This produced an electrode with a mirrorlike finish. Between each polishing step, the electrode was cleaned in an ultrasonic bath using an alkali solution. The steps for preparing a DPP electrode were as follows: (i) receive the electrode from the machine shop with " 32 " surface finish [25]; (ii) silicon carbide polishing with 300 grit paper to remove obvious visible scratches; (iii) solvent cleaning in ultrasonic bath of alkali solution; (iv) silicon carbide polishing with 600 grit paper; (v) solvent cleaning in ultrasonic bath of alkali solution; (vi) polish with $6 \mu \mathrm{m}$ grit; (vii) ultrasonic clean; (viii) polish with $3 \mu \mathrm{m}$ grit; (ix) ultrasonic clean; (x) high pressure rinsing (1200 psi) for 20 minutes with ultrapure deionized water with resistivity $>18 \mathrm{M} \Omega \mathrm{cm}$; and (xi) high temperature $\left(900^{\circ} \mathrm{C}\right.$ ) vacuum degas for one hour.

\section{B. Buffered chemical polishing of niobium}

Three different types of niobium electrodes were evaluated: single-crystal, large-grain (grain size $>$ few $\mathrm{cm}$ ) and fine-grain (also referred to as polycrystalline, grain size $\sim 0.13 \mathrm{~mm}$ ). The single-crystal and large-grain niobium test electrodes were manufactured from high quality material suitable for SRF cavity fabrication with residual resistance ratio (RRR) values $>250$. The finegrain niobium electrode was manufactured from "reactor grade" material with RRR value $\sim 40$. Machined electrodes were chemically etched in a mixture of hydrofluoric $(49 \%)$, nitric $(69 \%)$, and phosphoric $(85 \%)$ acid with mixing ratio $1: 1: 1$ at room temperature. This technique is referred to as buffered-chemical polishing. Typically, the desired surface finish was obtained after $\sim 20$ minutes immersion in the acid bath, corresponding to removal of $100 \mu \mathrm{m}$ of surface material. Besides taking advantage of the SRF technique of buffered-chemical polishing, other SRF techniques were adopted including high pressure rinsing and vacuum degassing [26]. The steps for preparing a polished niobium electrode were as follows: (i) receive the electrode from the machine shop with "32" surface finish [25]; (ii) silicon carbide polishing with 600 grit paper, if necessary, to remove obvious visible scratches; (iii) solvent cleaning in ultrasonic bath of alkali solution; (iv) buffered-chemical polishing to remove $\sim 100 \mu \mathrm{m}$ material; (v) high pressure rinsing (1200 psi) for 20 minutes with ultrapure deionized water with resistivity $>18 \mathrm{M} \Omega \mathrm{cm}$; and (vi) high temperature $\left(900^{\circ} \mathrm{C}\right)$ vacuum degas for one hour.

\section{Estimating the field strength using POISSON}

The electrostatic field mapping program POISSON [27] was used to estimate the field strength between cathode and anode, as a function of the applied cathode voltage and the cathode/anode gap. The highest surface field was located along an annular region with radius slightly larger than the portion of the electrode closest to the anode (Fig. 2).

\section{Krypton processing}

When stubborn field emitters would not burn off via conventional high voltage processing, the cathode samples were subjected to krypton processing [28]. This technique involved introducing a small amount of krypton gas into the vacuum chamber while the cathode electrode was biased at high voltage using a gap/field strength that produced significant field emission ( $\sim$ few $\mu \mathrm{As})$. It is believed the krypton becomes ionized in the presence of field emission and then attracted to the field emitters, changing their geometrical shape from sharp to blunt via sputtering [29]. Helium inert gas processing is a common
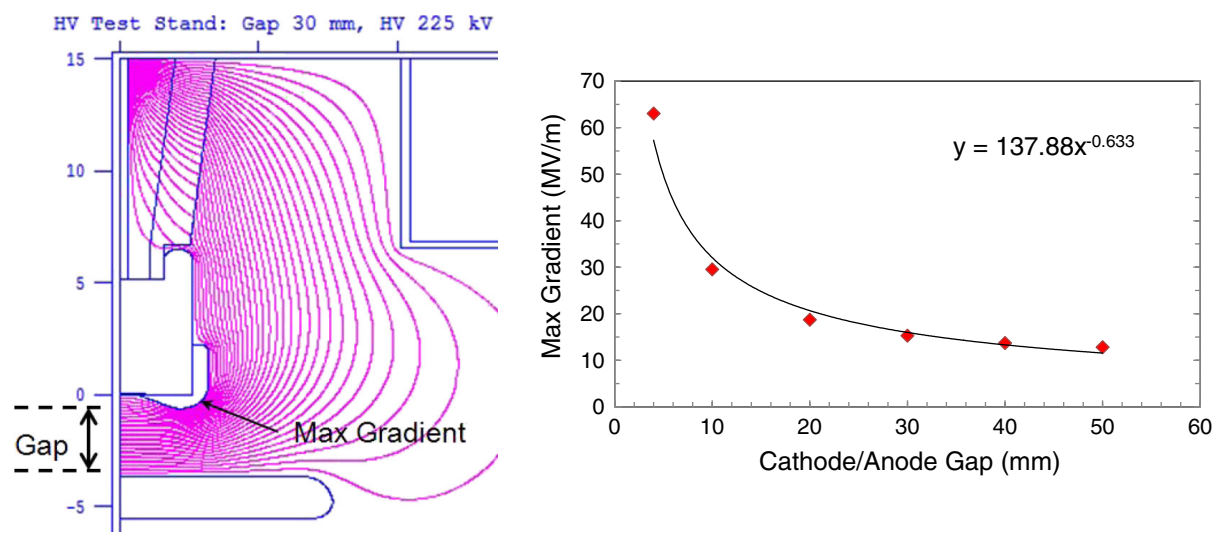

FIG. 2. (left) POISSON electrostatic field map showing lines of constant potential inside the field emission test apparatus. (right) Maximum field strength as a function of anode/cathode gap for $225 \mathrm{kV}$ cathode bias voltage. Data points are from POISSON and the line is a simple fit using a power function. 
technique to eliminate field emission inside SRF cavities [30], but is not very effective at eliminating field emission inside DC high voltage photoguns [28]. It is believed the heavier krypton gas imparts more kinetic energy to the field emitter.

Krypton was introduced to the vacuum apparatus via a leak valve set to provide pressure in the vicinity of the electrodes of $\sim 5 \times 10^{-6}$ Torr. This value was empirically determined to optimize the elimination of field emission. The anode current was monitored during krypton processing and a reduction in anode current was usually indicative of the elimination of a field emission site. Krypton processing typically was performed for 30 to 60 minutes, and could be repeated multiple times, depending on the performance of the test electrode.

Considerable care was taken to ensure the recovery of good vacuum post-krypton processing. The procedure involved continuously pumping the supplied krypton gas using a turbo pump appended to the apparatus behind a baked right angle valve. During krypton processing, the ion pump was turned off to avoid overburdening the pump with gas not efficiently pumped. When the krypton processing was completed, the krypton supply was terminated and the turbo pump was allowed to pump on the apparatus for an additional $\sim 15$ minutes. The ion pump was then reenergized and the valve to the turbo pump closed. Vacuum within the apparatus recovered relatively quickly ( $\sim 24$ hours) because care was taken to avoid backstreaming water vapor into the apparatus, and the nonevaporable getter pumps maintained high pump speed because they do not pump inert gases.

\section{RESULTS: FIELD EMISSION VERSUS VOLTAGE (I-V CURVES)}

A total of eight electrodes were evaluated-two each of DPP 304 stainless steel, fine-grain niobium, large-grain niobium, and single-crystal niobium. Some electrodes were evaluated more than once, i.e., the electrode was evaluated and then removed from the apparatus and inspected. If the electrode was exhibiting field emission at low voltage/field strength, sometimes it was repolished and the preparation steps repeated. If the electrode performed well, sometimes it was simply reinstalled in the apparatus and reevaluated. Upon initial application of high voltage, results were not always identical. It seems plausible that the variability of initial results for the same electrode can be attributed to contamination on the electrode surface. Typically, reproducible results were obtained following patient high voltage conditioning and krypton processing. More puzzling is the observation that results sometimes varied between electrodes of the same type. These variations might be a result of dissimilar surface finish or material imperfections present in one sample but not the other.

The field emission characteristics of the best electrode of each type are shown in Fig. 3. These I-V curves show field emission as a function of bias voltage and gap. The large-grain niobium performed the best, with no measurable field emission $(<10 \mathrm{pA})$ at $225 \mathrm{kV}$ for all gaps tested. It is particularly noteworthy that this sample required no krypton processing. This sample was removed from the apparatus, inspected using an optical
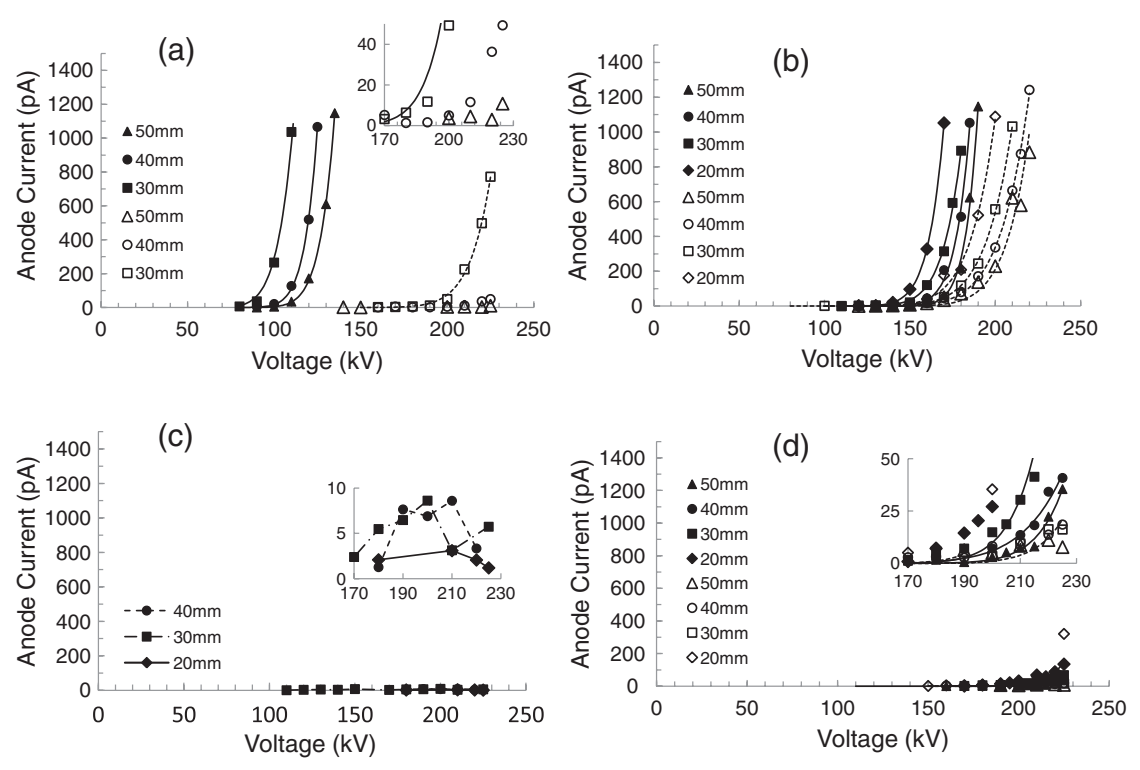

FIG. 3. Field emission current versus bias voltage and anode/cathode gap spacing for (a) DPP stainless steel, (b) fine-grain Nb, (c) large-grain $\mathrm{Nb}$, and (d) single-crystal $\mathrm{Nb}$. Each plot shows field emission behavior before (solid symbols) and after (open symbols) krypton processing, except for large-grain $\mathrm{Nb}$ which did not require krypton processing. Insets show an enhanced view of the low current data points. For all cases except large-grain $\mathrm{Nb}$, the lines between data points represent Fowler-Nordheim fits. 
profilometer at another facility, and reevaluated, with the same result.

The single-crystal niobium sample performed nearly as well at large-grain niobium. Fine-grain niobium performed the worst, with only modest improvement from krypton processing. DPP stainless steel exhibited the most variability in performance. The DPP stainless steel electrodes were tested multiple times and, frequently, exhibited no field emission at $225 \mathrm{kV}$ and $50 \mathrm{~mm}$ gap. However, frequently during evaluation at smaller gaps and larger fields, the electrode would begin to field emit. Krypton processing could usually restore good performance but often, the cycle of good-to-bad performance would repeat when evaluation at smaller gaps was revisited.

\section{RESULTS: FIELD EMISSION VERSUS FIELD STRENGTH (I-E CURVES)}

The field strength at which each electrode exhibited $100 \mathrm{pA}$ of field emission current is shown in Table I and plotted as a function of gap in Fig. 4. The value 100 pA was chosen because it would have a noticeable negative impact on GaAs photocathode lifetime if it were present in a photogun, and it was enough field emission to accurately apply the Fowler-Nordheim fit to the data. Table I and Fig. 4 include results from all the electrodes, not just the best performers that were highlighted in Fig. 3. For entries with $(>)$ symbol, field emission current did not exceed $100 \mathrm{pA}$ at $225 \mathrm{kV}$ bias voltage, the maximum voltage available. Consequently, the strength required to produce $100 \mathrm{pA}$ field emission must exceed the highest field accessible for the stated gap (red line in Fig. 4).

The black lines connecting data points in Fig. 4 are simple power-law fits to aid the eye and do not represent a functional form associated with a specific mathematical model of field emission. For some of the electrodes-finegrain niobium, in particular-the onset of field emission occurred at higher field strengths when the cathode/anode gap was small. This behavior is representative of the trends observed by Furuta et al. [19]. But for other electrodes, the onset of field emission was fairly insensitive to gap, and even trended in the opposite manner, with the onset of field emission occurring at lower field strengths for small gaps. These differing trends are important from a practical point of view and likely speak to interesting physics, but are not well understood.

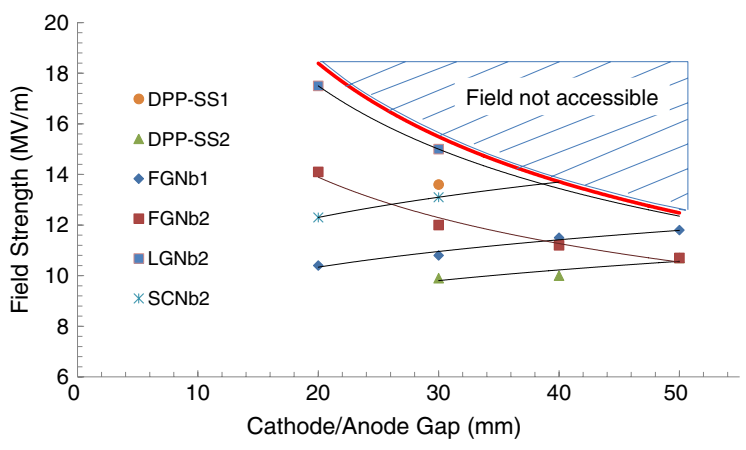

FIG. 4. The field strength at which each electrode exhibited $100 \mathrm{pA}$ of field emission as a function of anode/cathode gap. For LGNb1 and SCNb1, the field exceeded values denoted by the red line for all gaps. For LGNb2, SCN2, and DPP-SS1, the field exceeded values above the red line at 40 and $50 \mathrm{~mm}$ gaps. Black lines represent simple power-law fits to aid the eye.

\section{DISCUSSION: FOWLER-NORDHEIM ANALYSIS}

The I-V curves were replotted using the FowlerNordheim line-plot representation to determine the field enhancement factor $\beta$. Figure 5 shows a typical line-plot result, before and after krypton processing, for large-grain niobium. The benefit of krypton processing is dramatically evident, with a reduction in $\beta$ from 368 to 173. Table II summarizes the field enhancement factors for all electrodes that exhibited sufficient levels of field emission. For these calculations, a work function of $4.3 \mathrm{eV}$ was used for all forms of niobium, and $4.5 \mathrm{eV}$ for stainless steel. For most of the entries in Table II, the field enhancement factor was constant to within 5 to $20 \%$ for each gap. There are a few examples where the field enhancement factor of an electrode varied markedly at a particular gap, suggesting the birth of a new field emitter. In hindsight, further processing was likely required.

Two electrodes (single-crystal Nb1 and large-grain Nb1) did not exhibit enough field emission to apply the FowlerNordheim functional fit to the data. For these electrodes, $\beta$ can be assumed to be smaller than values measured for the other electrodes.

The field enhancement factor for all electrodes decreased significantly following krypton processing, with one exception (fine-grain $\mathrm{Nb} 2$ ) and this anomaly is not understood. It is common to assume $\beta$ to be proportional to the ratio of the height of the emitter to the radius of the

TABLE I. The field strength required to produce $100 \mathrm{pA}$ of field emission, following krypton processing. For entries with $(>$ ) symbol, field emission current did not exceed $100 \mathrm{pA}$ at $225 \mathrm{kV}$ bias voltage, the maximum voltage available.

\begin{tabular}{lcccccccc}
\hline \hline & FGNb1 & FGNb2 & SCNb1 & SCNb2 & LGNb1 & LGNb2 & DPP-SS1 & DPP-SS2 \\
\hline $50 \mathrm{~mm}$ & 11.8 & 10.7 & $>12.6$ & $>12.6$ & $>12.6$ & $>12.6$ & $>12.6$ & 10.7 \\
$40 \mathrm{~mm}$ & 11.5 & 11.2 & $>13.8$ & $>13.8$ & $>13.8$ & $>13.8$ & $>13.8$ & 10.0 \\
$30 \mathrm{~mm}$ & 10.8 & 12.0 & $>15.0$ & 13.1 & $>15.0$ & 15.0 & 13.6 & 9.9 \\
$20 \mathrm{~mm}$ & 10.4 & 14.1 & $>18.7$ & 12.3 & $>18.7$ & 17.5 & No data & No data \\
\hline \hline
\end{tabular}




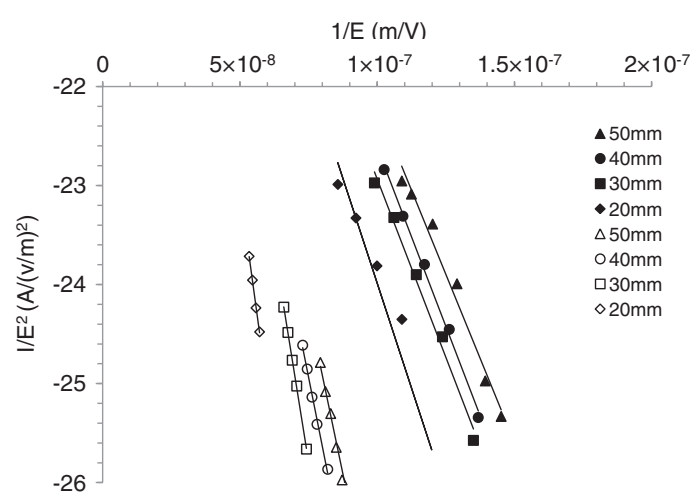

FIG. 5. Example of Fowler-Nordheim line plots for large-grain niobium before (solid symbols) and after (open symbols) krypton processing.

emitter. Large $\beta$ values describe tall protrusions, and/or protrusions with small radius. It is reasonable to assume that krypton processing can reduce the height of emitters due to ion bombardment, with emitter material sputtered

TABLE II. $\quad \beta$ values for all eight electrodes, before and after krypton processing.

\begin{tabular}{|c|c|c|c|c|c|}
\hline Pre-krypton & $50 \mathrm{~mm}$ & $40 \mathrm{~mm}$ & $30 \mathrm{~mm}$ & $20 \mathrm{~mm}$ & Avg \\
\hline FGNb1 & 696 & 738 & 764 & 743 & 735 \\
\hline FGNb2 & 394 & 328 & 261 & 268 & 313 \\
\hline $\mathrm{SCNb} 1^{\mathrm{a}}$ & $\ldots$ & $\ldots$ & $\ldots$ & $\ldots$ & $\ldots$ \\
\hline $\mathrm{SCNb} 2$ & 615 & 565 & 494 & 454 & 532 \\
\hline $\mathrm{LGNb}^{\mathrm{a}}$ & $\ldots$ & $\ldots$ & $\ldots$ & $\ldots$ & $\ldots$ \\
\hline LGNb2 & 399 & 375 & 377 & 320 & 368 \\
\hline DPP-SS1 & 754 & 670 & 703 & No data & 709 \\
\hline DPP-SS2 & 1118 & 796 & 1156 & No data & 1023 \\
\hline Post-krypton & $50 \mathrm{~mm}$ & $40 \mathrm{~mm}$ & $30 \mathrm{~mm}$ & $20 \mathrm{~mm}$ & Avg \\
\hline FGNb1 & 263 & 387 & 260 & 268 & 295 \\
\hline FGNb2 & 687 & 698 & 648 & 478 & 628 \\
\hline $\mathrm{SCNb} 1^{\mathrm{a}}$ & $\ldots$ & $\ldots$ & $\ldots$ & $\ldots$ & $\ldots$ \\
\hline $\mathrm{SCNb} 2$ & 349 & 490 & 231 & 232 & 326 \\
\hline $\mathrm{LGNb}^{\mathrm{a}}$ & $\cdots$ & $\ldots$ & $\cdots$ & $\cdots$ & $\ldots$ \\
\hline LGNb2 & 205 & 196 & 156 & 136 & 173 \\
\hline DPP-SS1 & 214 & 684 & 301 & No data & 400 \\
\hline DPP-SS2 & 394 & 279 & 276 & No data & 316 \\
\hline
\end{tabular}

${ }^{\mathrm{a}}$ Beta could not be determined for these electrodes because there was too little field emission to provide an accurate FowlerNordheim line-plot fit. away. In this view, it difficult to understand how krypton processing could increase the size of the field enhancement factor for fine-grain $\mathrm{Nb} 2$.

As mentioned previously, the $y$-axis intercept of the Fowler-Nordheim line plot is related to the surface area of the field emitter. Emitter area values are shown in Table III. All of the emitter area values are extremely small, especially considering that Ref. [23] predicts typical field emitter areas $10^{-16}<A_{e}<10^{-12} \mathrm{~m}^{2}$. This is likely an indication that field emission originates from multiple locations whereas traditional Fowler-Nordheim theory assumes just one emitter. In addition, Table III indicates that emission area increases following krypton processing. This might be explained by krypton ions sputtering away sharp tips, making them more rounded, or blunt. It might also be related to a greatly reduced number of field emitters contributing to the total measured current.

\section{OPTICAL PROFILOMETER IMAGES AND SURFACE ROUGHNESS}

After characterizing field emission performance in the high voltage test apparatus, each electrode was studied using an optical profilometer [31], to look for obvious field emitters and to determine surface roughness. An optical profilometer does not contact the surface of the specimen under investigation. Two roughness numbers are reported for each electrode in Table IV: one quantity describes a periodic large-scale roughness (or waviness) and the other quantity describes roughness on a fine scale. The same profilometer data file was used to determine both quantities but using different spatial filtering. The periodic roughness/ waviness was determined by applying a low-pass filter to the data file, to eliminate fine-scale variations, and is therefore somewhat subjective. Waviness originates from the machining process and relates to how fast the cutting tool was moved across the electrode during fabrication. The fine-scale roughness quantity is considered to be the more relevant metric when considering field emission.

False-color images of representative electrodes are shown in Fig. 6. Each image represents a portion of the electrode near the crown, in the vicinity of the region exposed to high field. Fine-grain niobium had the roughest surface finish (200 to $300 \mathrm{~nm}$ ), and perhaps not surprisingly exhibited the highest levels of field emission. Single-crystal

TABLE III. Fowler-Nordheim line-plot intercept values and emission areas, assuming all of the field emission originates from a single emitter.

\begin{tabular}{|c|c|c|c|c|c|c|c|c|}
\hline & FGNb1 & FGNb2 & $\mathrm{SCNb}^{\mathrm{a}}$ & $\mathrm{SCNb} 2$ & $\mathrm{LGNb}^{\mathrm{a}}$ & LGNb2 & DPP-SS1 & DPP-SS2 \\
\hline Intercept Pre-Kr & -17.8 & -15.8 & $\ldots$ & -18.5 & & -15.5 & -17.6 & -18.3 \\
\hline Intercept Post-Kr & -15.5 & -20.3 & $\cdots$ & -17.4 & $\ldots$ & -13.7 & -22.6 & -15.4 \\
\hline$A_{e}$ Pre-Kr & $5.5 \times 10^{-25}$ & $1.9 \times 10^{-22}$ & $\ldots$ & $1.2 \times 10^{-25}$ & $\ldots$ & $6.2 \times 10^{-24}$ & $6.4 \times 10^{-25}$ & $8.3 \times 10^{-25}$ \\
\hline$A_{e}$ Post-Kr & $7.8 \times 10^{-23}$ & $1.1 \times 10^{-27}$ & $\ldots$ & $2.0 \times 10^{-23}$ & $\ldots$ & $8.4 \times 10^{-22}$ & $1.7 \times 10^{-25}$ & $1.2 \times 10^{-22}$ \\
\hline
\end{tabular}

${ }^{\mathrm{a}}$ Information could not be determined for these electrodes because there was too little field emission to provide an accurate FowlerNordheim line-plot fit. 
TABLE IV. Surface roughness values of all electrodes obtained using an optical profilometer.

\begin{tabular}{llcccccr}
\hline \hline & FGNb1 & FGNb2 & SCNb1 & SCNb2 & LGNb1 & LGNb2 & DPP-SS1 \\
\hline Roughness $(\mathrm{nm})$ & 303.95 & 215.1 & 17.6 & 10.2 & 141.01 & 51.98 & 10.9 \\
Waviness $(\mathrm{nm})$ & 545.4 & 565.5 & 71.1 & 107.7 & 452.6 & 372.1 & 25.3 \\
\hline \hline
\end{tabular}

niobium and DPP stainless steel electrodes had the smoothest surface finish (10 to $20 \mathrm{~nm}$ ) and interestingly singlecrystal niobium performed very well whereas DPP stainless steel frequently exhibited high levels of field emission. Perhaps most surprisingly, large-grain niobium had midlevel roughness but exhibited the lowest levels of field emission. Good performance despite a rough surface could be due to a "screening effect" that serves to reduce the field enhancement factor $\beta$ [32]. Beneficial screening requires that field emitter protrusions occur on the surface of the electrode with the correct spatial periodicity. This is illustrated in Fig. 7, showing images of both large-grain $\mathrm{Nb}$ electrodes. Large-grain niobium1 exhibited a rough surface composed of closely spaced ridges and this likely proved
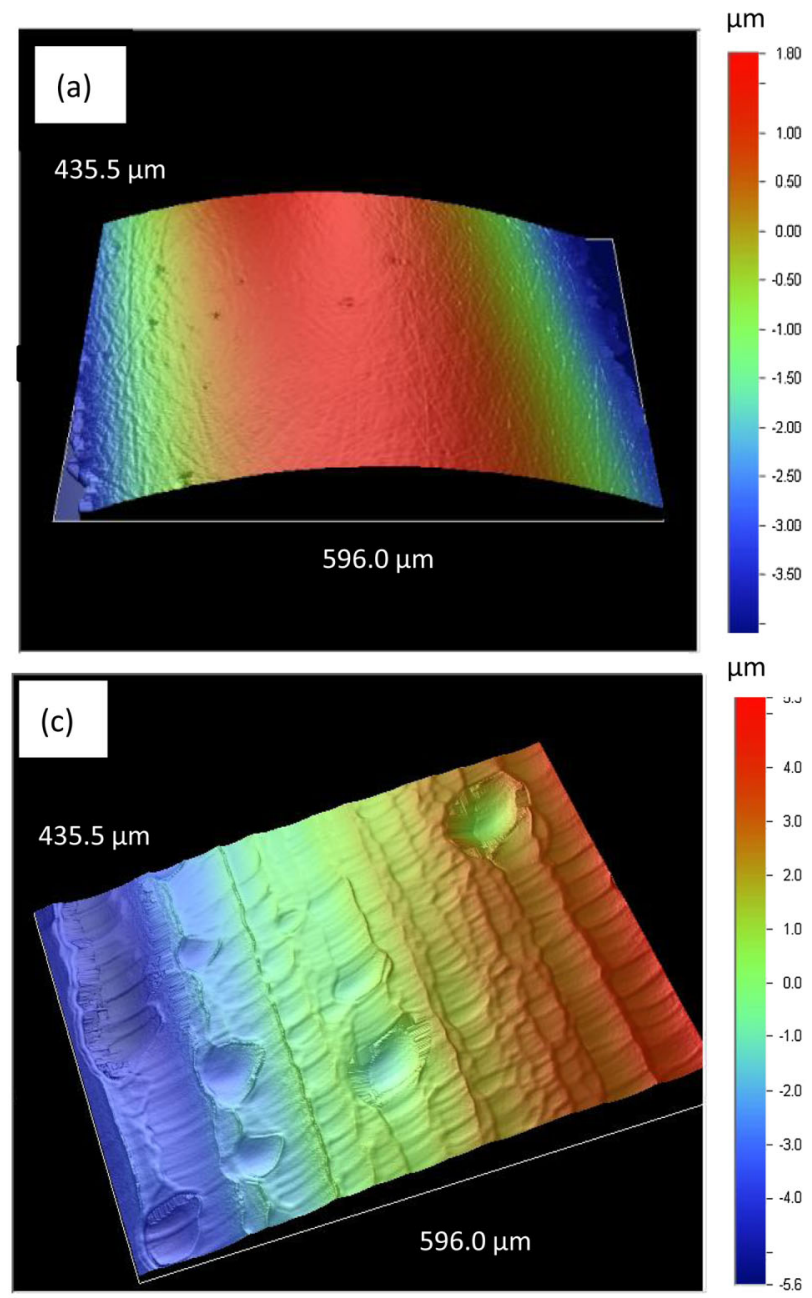

fortuitous - the spacing of the ridges presumably served to reduce the effective height of individual ridges, with only a shallow penetration of field lines between ridges.

The surface of some of electrodes-in particular largegrain and single-crystal niobium-exhibited shallow craters. An iterative profilometer analysis of a large-grain niobium electrode indicated that the craters were not visible before the application of high voltage, and the craters were not a result of krypton processing. As such, a crater is likely an indication of a field emission site (either active or inactive). Typical crater dimensions are 20 to $50 \mu \mathrm{m}$ diameter and 0.2 to $1 \mu \mathrm{m}$ deep. The crater pattern for large-grain niobium was random although, frequently, craters were centered on the top of ridges. For single-crystal
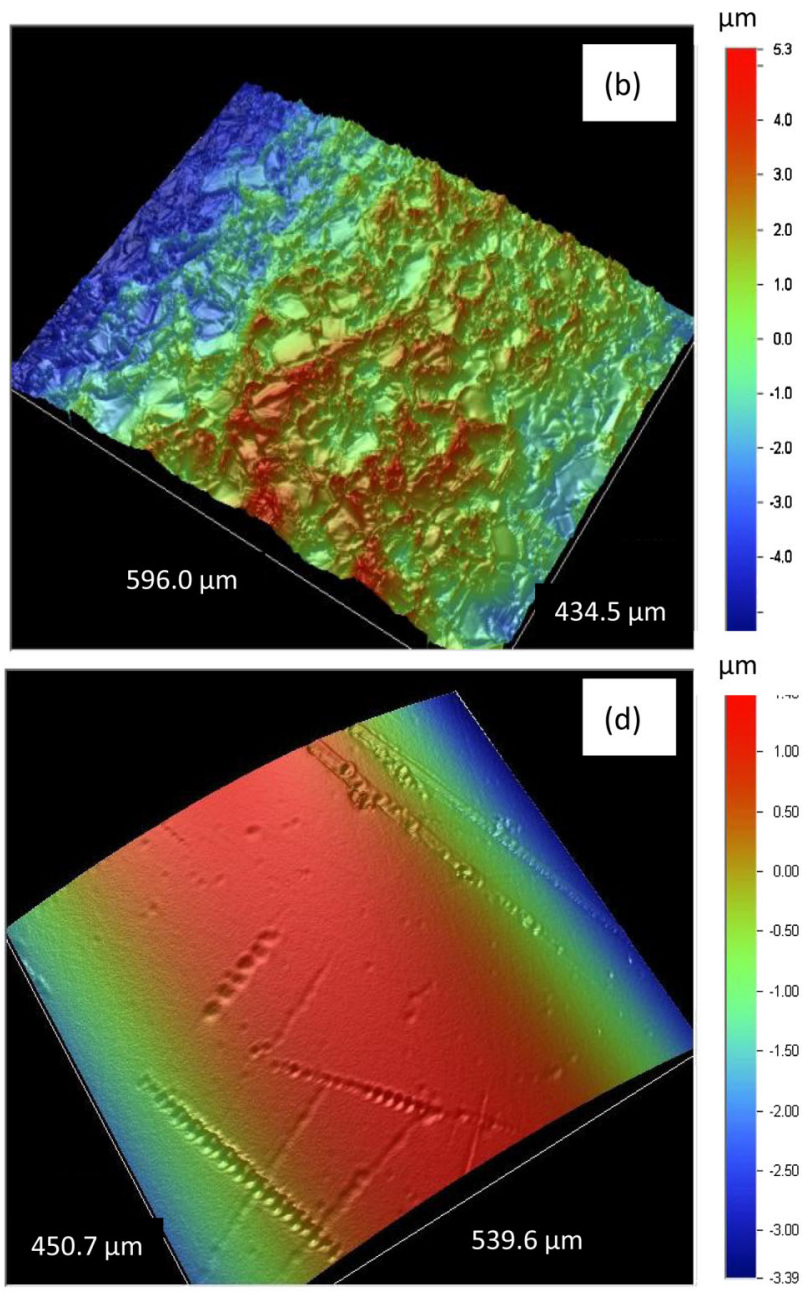

FIG. 6. Optical profilometer images of (a) DPP 304 stainless steel, (b) fine-grain niobium, (c) large-grain niobium, and (d) singlecrystal niobium. The span of each image is very nearly the same, approximately $450 \mu \mathrm{m} \times 600 \mu \mathrm{m}$. 

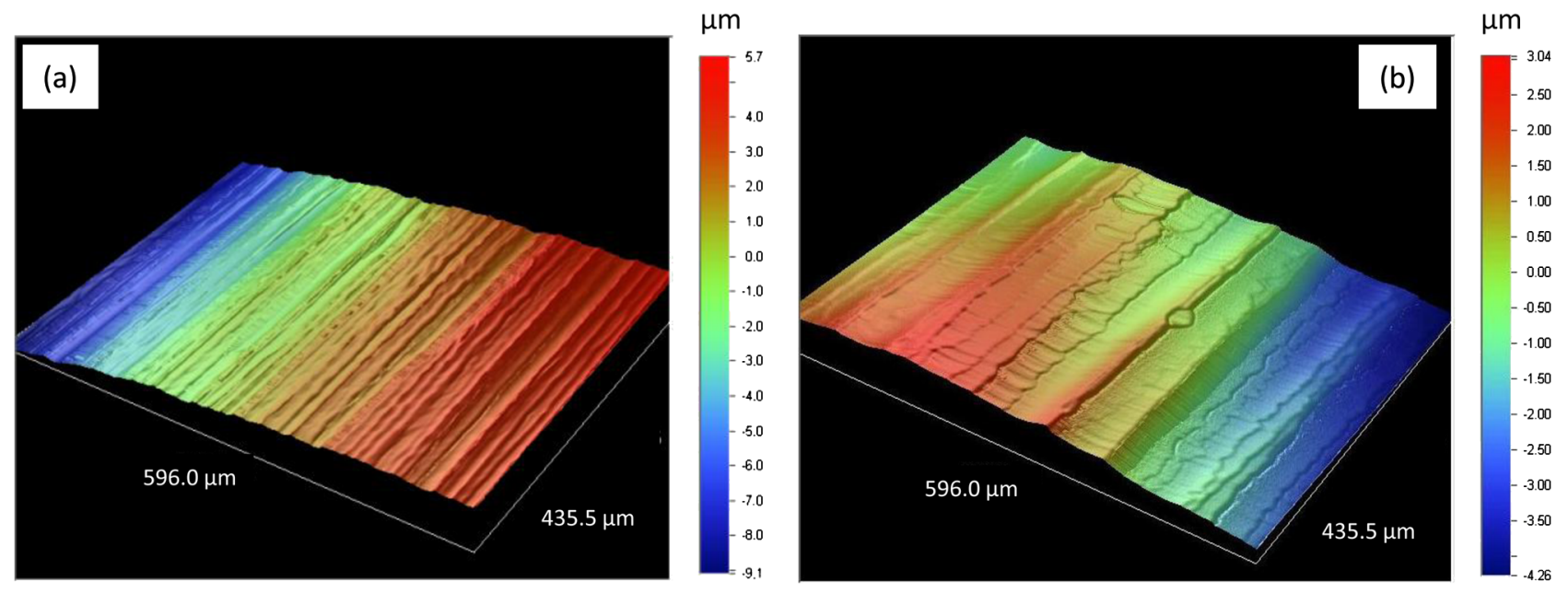

FIG. 7. Optical profilometer images of both large-grain niobium electrodes: (a) sample\#1 with surface roughness $141 \mathrm{~nm}$, and (b) sample\#2 with surface roughness $52 \mathrm{~nm}$. Large-grain niobium sample\#1, with rougher surface, performed the best.

niobium, craters appeared along lines that indicate the presence of microscratches. Similar craters might be present on the surface of fine-grain niobium but indistinguishable due to scale of the grain boundaries of these materials. No craters were visible for DPP stainless steel.

The surface features of the eight test electrodes described above are significantly larger than the emitter area dimensions predicted by the Fowler-Nordheim lineplot analysis (Table III), which supports the notion that for large smooth electrodes, the observed field emission is likely a result of multiple field emitters. To test the validity of this assertion, a third DPP stainless steel electrode with a known field emitter-or more plainly, an electrode with a clearly defined scratch - was evaluated in the field emission test stand. The scratch was $70 \mathrm{~nm}$ "tall" (peak to valley) and $1.1 \mathrm{~cm}$ long. As expected, field emission was observed at low voltages and field strength and a FowlerNordheim line-plot analysis of the results indicated a field enhancement factor of 444 and emitting area of $2.3 \times 10^{-10} \mathrm{~m}^{2}$. The field enhancement factor $\beta$ is also frequently defined as the ratio of emitter height to emitter radius. Using the $\beta$ value from the Fowler-Nordheim lineplot analysis and the emitter height value from the optical profilometer measurement, the emitter radius was estimated to be $0.16 \mathrm{~nm}$. The radius and the length of the scratch can be used to estimate the geometric area of the emitter $\left(A_{e}=\pi \cdot r \cdot l\right)$, or $5.5 \times 10^{-12} \mathrm{~m}^{2}$. So although the two values for $A_{e}$ differ by a factor of 42 , this is considerably better agreement compared to the emitter area assessment of large smooth electrodes. This suggests that when field emission originates from a single emitter, a Fowler-Nordheim line-plot analysis can provide quantitative insight into the physical characteristics of the emitter.

\section{CONCLUSIONS}

Large-grain niobium appears to be excellent choice for manufacturing electrodes for DC high voltage photoguns, reaching higher voltages and field strengths without field emission, compared to diamond-paste polished stainless steel. One sample of large-grain niobium performed the best, reaching $225 \mathrm{kV}$ and $18.7 \mathrm{MV} / \mathrm{m}$ without measurable field emission. This electrode performed well during initial testing and upon repeated reevaluation. Large-grain niobium is readily available, for example, compared to single-crystal niobium, which also performed well. In contrast, "reactor grade" fine-grain niobium with RRR value $\sim 40$ exhibited comparatively high levels of field emission. Fine-grain niobium with RRR value $>250$ will be evaluated in the future. All of the niobium electrodes were prepared in less time compared to DPP stainless steel electrodes.

Sometimes, results varied significantly for the same electrode and/or for different electrodes of the same material. This variability complicates the process of assigning firm conclusions. The performance of an electrode could be improved significantly via krypton processing. It seems reasonable to assume krypton processing served to eliminate field emission stemming from random contamination. Besides providing a very practical means to reduce field emission from an electrode, the authors feel that krypton processing served as a useful tool to reduce the variability in field emission results.

A traditional Fowler-Nordheim line-plot analysis of the field emission results was easy to perform but of marginal practical value, largely because the Fowler-Nordheim theory assumes a single field emitter and for large electrodes, this does not seem to be realistic.

Optical profilometry indicated that a smooth surface does not guarantee cathode performance free of field emission however it did provide a possible explanation for why one large-grain niobium electrode performed better than the other electrode, namely, a surface with periodic structure served to lower the field enhancement factor via a process termed screening. Optical profilometry also 
provided useful information related to the physical characteristics of field emission sites (i.e., dimensions), although it is not known if the observed craterlike structures on the surface of large-grain and single-crystal niobium electrodes represent active or inactive field emission sites.

\section{ACKNOWLEDGMENTS}

This paper was authored by Jefferson Science Associates under U.S. DOE Contract No. DE-AC0584ER40150 and with funding from the DOE Office of High Energy Physics and the Americas Region ILC R\&D program. Thanks to Peter Kneisel, Larry Turlington, Teena Harris, Scott Williams, and Tom Elliott of the JLab SRF Institute for extensive help preparing the niobium electrodes. Thanks to Maria Chetsova for generating the initial POISSON electrostatic field maps.

[1] C. K. Sinclair, ICFA Newsletter 46, 97 (2008).

[2] The Physics and Applications of High Brightness Electron Beams, edited by Jamie Rosenzweig, Gil A. Travish, and Luca Serafi (World Scientific, Singapore, 2003).

[3] I. V. Bazarov and C.K. Sinclair, Phys. Rev. ST Accel. Beams 8, 034202 (2005); I. V. Bazarov, B. M. Dunham, and C. K. Sinclair, Phys. Rev. Lett. 102, 104801 (2009).

[4] C. K. Sinclair, E.L. Garwin, R.H. Miller, and C. Y. Prescott, AIP Conf. Proc. 35, 424 (1976); C. Y. Prescott et al., Phys. Lett. B 77, 347 (1978).

[5] R. Alley, H. Aoyagi, J. Clendenin, J. Frisch, C. Garden, E. Hoyt, R. Kirby, L. Klaisner, A. Kulikov, R. Miller, G. Mulhollan, C. Prescott, P. Saez, D. Schultz, H. Tang, J. Turner, K. Witte, M. Woods, A. D. Yeremian, and M. Zolotorev, Nucl. Instrum. Methods Phys. Res., Sect. A 365, 1 (1995).

[6] W. Hartmann, D. Conrath, W. Gasteyer, H. J. Gessinger, W. Heil, H. Kessler, L. Koch, E. Reichert, H. G. Andresen, T. Kettner, B. Wagner, J. Ahrens, J. Jethwa, and F. P. Schafer, Nucl. Instrum. Methods Phys. Res., Sect. A 286, 1 (1990).

[7] K. Aulenbacher, Ch. Nachtigall, H. G. Andresen, J. Bermuth, Th. Dombo, P. Drescher, H. Euteneuer, H. Fischer, D. v. Harrach, P. Hartmann, J. Joffmann, P. Jennewein, K. H. Kaiser, S. Kobis, H. J. Kreidel, J. Langbein, M. Petri, S. Plutzer, E. Reichert, M. Schemies, H.-J. Schope, K. H. Steffens, M. Steigerwald, H. Trautner, and Th. Weis, Nucl. Instrum. Methods Phys. Res., Sect. A 391, 498 (1997).

[8] G. D. Cates, V. W. Hughes, R. Michaels, H. R. Schaefer, T. J. Gay, M. S. Lubell, R. Wilson, G. W. Dodson, K. A. Dow, S. B. Kowalski, K. Isakovich, K. S. Kumar, M.E. Schulze, P. A. Souder, and D. H. Kim, Nucl. Instrum. Methods Phys. Res., Sect. A 278, 293 (1989); E. Tsentalovich, D. Barkhuff, J. Chen, G. Dodson, M. Farkhondeh, W. Franklin, E. Ihloff, F. Kaertner, C.
Tschalaer, B. Yang, and T. Zwart, Nucl. Instrum. Methods Phys. Res., Sect. A 582, 413 (2007).

[9] M. J. J. van den Putte, C. W. De Jager, S. G. Konstantinov, V. Ya. Korchagin, F. B. Kroes, E. P. van Leeuwen, B. L. Militsyn, N.H. Papadakis, S.G. Popov, G. V. Serdobintsev, Yu. M. Shatunov, S. V. Shevelev, T. G. B.W. Sluijk, A. S. Terekhov, and Yu. F. Tokarev, AIP Conf. Proc. 421, 260 (1998); M. J. J. van den Putte, C. W. de Jager, B. L. Militsyn, Yu. M. Shatunov, and Yu. F. Tokarev, Nucl. Instrum. Methods Phys. Res., Sect. A 406, 50 (1998).

[10] W. Hillert, M. Gowin, and B. Neff, AIP Conf. Proc. 570, 961 (2001).

[11] T. Siggins, C. Sinclair, C. Bohn, D. Bullarda, D. Douglas, A. Grippo, J. Gubeli, G. A. Krafft, and B. Yunn, Nucl. Instrum. Methods Phys. Res., Sect. A 475, 549 (2001).

[12] C. Hernandez-Garcia et al., in Proceedings of the 45th ICFA Advanced Beam Dynamics Workshop, Cornell University, Ithaca, NY, 2009, pp. 37-39.

[13] L. B. Jones, S.P. Jamison, Y.M. Saveliev, K. J. Middleman, and S. L. Smith, in Proceedings of the 18th International Symposium on High Energy Spin Physics (SPIN2008), AIP Conf. Proc. No. 1149 (AIP, New York, 2008), p. 1084.

[14] B. M. Dunham and K. W. Smolenski, Power Modulator and High Voltage Conference, 2010 (IEEE International, Atlanta GA, 2010).

[15] N. Nishimori, R. Nagai, H. Iijima, Y. Honda, T. Muto, M. Kuriki, M. Yamamoto, S. Okumi, T. Nakanishi, and R. Hajima, in Proceedings of the 18th International Symposium on High Energy Spin Physics (SPIN2008), AIP Conf. Proc. No. 1149 (AIP, New York, 2008), p. 1094; N. Nishimori, R. Nagai, H. Iijima, Y. Honda, T. Muto, M. Kuriki, M. Yamamoto, S. Okumi, T. Nakanishi, and R. Hajima, ERL11 (KEK, Japan, 2011).

[16] P. Adderley, J. Clark, J. Grames, J. Hansknecht, K. SurlesLaw, D. Machie, M. Poelker, M.L. Stutzman, and R. Suleiman, Phys. Rev. ST Accel. Beams 13, 010101 (2010).

[17] R. Nagai, R. Hajima, N. Nishimori, T. Muto, M. Yamamoto, Y. Honda, T. Miyajima, H. Iijima, M. Kuriki, M. Kuwahara, S. Okumi, and T. Nakanishi, Rev. Sci. Instrum. 81, 033304 (2010).

[18] N. D. Theodore, B. C. Holloway, D. M. Manos, R. Moore, C. Hernandez, T. Wang, and H.F. Dylla, IEEE Trans. Plasma Sci. 34, 1074 (2006); C. K. Sinclair et al., in Proceedings of the Particle Accelerator Conference, Chicago, IL, 2001 (IEEE, New York, 2001).

[19] F. Furuta et al., Nucl. Instrum. Methods Phys. Res., Sect. A 538, 33 (2005).

[20] C. K. Sinclair et al., in Proceedings of the Particle Accelerator Conference, Chicago, IL, 2001 (Ref. [18]).

[21] C.E. Reece and G. Ciovati, "Reviews of Accelerator Science and Technology Volume 5" (World Scientific, Singapore, to be published).

[22] R. H. Fowler and L. Nordheim, Proc. R. Soc. A 119, 173 (1928).

[23] R. V. Latham, High Voltage Vacuum Insulation (Academic Press, London, 1995).

[24] C. K. Sinclair, P. A. Adderley, B. M. Dunham, J.C. Hansknecht, P. Hartmann, M. Poelker, J. S. Price, P. M. 
Rutt, W. J. Schneider, and M. Steigerwald, Phys. Rev. ST Accel. Beams 10, 023501 (2007).

[25] A. M. Wagener and H. R. Arthur, Machine Shop Theory and Practice (D. Van Nostrand Company, New York, 1950). A specified surface finish governs the speed at which the cutting tool moves across the surface of the electrode. For a 32 surface finish, the grooves left by the cutting tool are no more than 32 mircoinches apart.

[26] P. Kneisel, in Proceedings of the 32nd Advanced ICFA Beam Dynamics Workshop on Energy Recovering Linacs, edited by S. Chattopadhay and L. Merminga [Nucl. Instrum. Methods Phys. Res., Sect. A, 557 (2006)].

[27] K. Halbach, Lawrence Livermore National Laboratory Technical Report No. UCRL-17436, 1967.

[28] C. Hernandez-Garcia, S. V. Benson, G. Biallas, D. Bullard, P. Evtushenko, K. Jordan, M. Klopf, D. Sexton,
C. Tennant, R. Walker, and G. Williams, in Proceedings of the 18th International Symposium on High Energy Spin Physics (SPIN2008), AIP Conf. Proc. No. 1149 (AIP, New York, 2008), p. 1071.

[29] D. Alpert, D. Lee, E. M. Lyman, and H.E. Tomaschke, J. Appl. Phys. 38, 880 (1967).

[30] C. E. Reece, M. Drury, M. G. Rao, and V. Nguyen-Tuong, in Proceedings of the Particle Accelerator Conference, Vancouver, BC, Canada, 1997 (IEEE, New York, 1997), p 3105.

[31] B. Bhushan, J.C. Wyant, and J. Meiling, Wear 122, 301 (1988); V. Filip, D. Nicolaescu, M. Tanemura, and F. Okuyama, Ultramicroscopy 89, 39 (2001).

[32] L. Nilsson, O. Groening, C. Emmenegger, O. Kuettel, E. Schaller, L. Schlapbach, H. Kind, J.-M. Bonard, and K. Kern, Appl. Phys. Lett. 76, 2071 (2000). 